\title{
Improving the accuracy of infrared measurements of skin temperature
}

\author{
Allen Curran", Mark Klein, Mark Hepokoski, Corey Packard \\ From 15th International Conference on Environmental Ergonomics (ICEE XV) \\ Portsmouth, UK. 28 June - 3 July 2015
}

\begin{abstract}
Introduction
In principle, infrared (IR) imagery of exposed skin and clothing can provide a valuable source of data for thermo-physiological studies. In practice, and despite the fall in the cost of IR cameras, infrared imagery is not universally collected during human subject testing. One reason for this may be the relatively poor accuracy of IR cameras (typically $\pm 2{ }^{\circ} \mathrm{C}$ ). The repeatability of the measurements taken with a particular IR camera (both spatially and temporally) is much better than its accuracy, i.e., close to the camera's sensitivity. An IR camera's sensitivity (and repeatability) is typically on the order of hundredths of a degree Celsius. Consequently, a reference with known temperature and emissivity placed in the camera's field-of-view when taking measurements can provide two potential benefits: First, measurement error can be reduced by using a calibration procedure. Second, IR imagery taken by different IR cameras during different test episodes can be directly compared.
\end{abstract}

\section{Methods}

Two IR cameras (a FLIR E60 and a FLIR ONE) were used to collect IR imagery during a simple human subject test. An IR thermometer (Omega OSXL450) was also used to make spot temperature measurements. Calibration curves (that map instrument readings to reference temperatures) were created for the IR cameras and the thermometer using a hot/cold blackbody calibration source (Omega BB701). The test subjects were asked to sit outside without jackets for 10 minutes where the ambient temperature was $4{ }^{\circ} \mathrm{C}$. The subjects were subsequently brought indoors where the ambient temperature was approximately $20{ }^{\circ} \mathrm{C}$. Forehead skin temperature measurements were made using the IR cameras and the IR thermometer. The hot/cold blackbody and a second heated-only blackbody (Omega BB702) were placed in the field-of-view of the cameras to provide reference temperatures that could be used to correct the measured forehead temperature through interpolation. Calibration procedures were evaluated by examining the bias [1] between the measurements made of the same forehead skin temperature.

\section{Results}

Measured forehead temperatures for a single individual are shown below, before and after correction using the calibration curve and the in-scene blackbodies.

\section{Discussion}

The calibration procedure did not appear to positively impact measurements made with the FLIR ONE. Calibration did improve the bias between measurements made with the FLIR E60 and the Omega OSXL 450 from $1.0{ }^{\circ} \mathrm{C}$ (uncorrected) to $0.58{ }^{\circ} \mathrm{C}$ (corrected with the calibration curve) to $0.48{ }^{\circ} \mathrm{C}$ (corrected with the inscene blackbodies).

\section{Conclusion}

Both calibration procedures improved the agreement between measurements made with the FLIR E60 and the Omega OSXL450. Placing blackbodies in the camera's field of view has the advantage of ensuring that the calibration information is always available and current. The FLIR ONE, which is a low-cost IR camera marketed to consumers, does not appear suitable for collecting absolute temperature data even when a calibration procedure is employed.

Published: 14 September 2015

* Correspondence: Allen.Curran@ThermoAnalytics.com

ThermoAnalytics, Inc., Calumet, MI, USA 


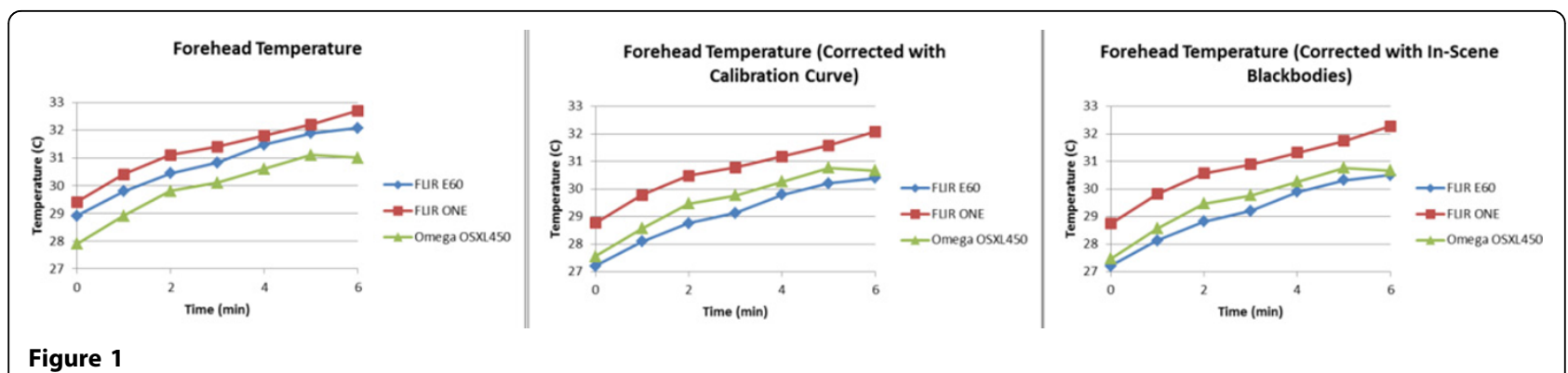

\section{Reference}

1. Psikuta Agnes, et al: Validation of the Fiala multi-node

thermophysiological model for UTCI application. International Journal of Biometeorology 2012, 56(3):443-460, May.

doi:10.1186/2046-7648-4-S1-A140

Cite this article as: Curran et al.: Improving the accuracy of infrared measurements of skin temperature. Extreme Physiology \& Medicine 2015 4(Suppl 1):A140.

Submit your next manuscript to BioMed Central and take full advantage of:

- Convenient online submission

- Thorough peer review

- No space constraints or color figure charges

- Immediate publication on acceptance

- Inclusion in PubMed, CAS, Scopus and Google Scholar

- Research which is freely available for redistribution

Submit your manuscript at www.biomedcentral.com/submit 